Hispania Sacra, LX

122, julio-diciembre 2008, 467-484, ISSN: 0018-215-X

\title{
REDES, REFORMA Y REVOLUCIÓN: DOS FRANCISCANOS RIOPLATENSES SOBREVIVIENDO AL SIGLO XIX (1800-1830**
}

\author{
POR \\ JoRGE TROISI-MELEAN \\ Universidad Nacional de la Plata
}

\section{RESUMEN}

En este trabajo, de carácter exploratorio, he procurado realizar un recorrido histórico de las primeras tres décadas del siglo XIX en el Río de la Plata a través de la vida de dos importantes franciscanos. Usando archivos eclesiásticos y civiles, sermones y diarios, intento identificar de qué manera, diferentes acontecimientos de largo alcance trasformaron las vidas de dos hispanoamericanos. A partir de dos historias de vida pretendo brindar algunas sugerencias sobre el funcionamiento en el ámbito local de las políticas borbónicas, el impacto de la revolución dentro y fuera de los conventos, la transformación ideológica dentro de las Órdenes regulares y las intrincadas redes de relaciones sociales a ambos lados del Atlántico.

PALABRAS CLAVE: Franciscanos, redes, reforma, sermones prensa revolución.

\section{NETWORKS, REFORM AND REVOLUTION: TWO FRANCISCANS FROM THE RIVER PLATE REGION SURVIVING TO THE XIXTH CENTURY (1800-1830)}

\section{ABSTRACT}

In this article we try to analyze the first three decades of the 19th century in the Río de la Plata region through the lives of two important Franciscans. Using

\footnotetext{
* Una primera versión de este trabajo fue presentada en las «Primeras Jornadas Nacionales de Historia Social», mayo y junio del 2007, La Falda, Córdoba.
} 
civil and ecclesiastical documents, sermons and newspapers we will try to identify in which ways, different events changed the lives of two members of the Catholic Church. Two life stories are the windows to analyze the effect of the Bourbon Reforms at a local level, the impact of the revolution inside and outside the convents, the ideological transformation of the Clergy and the different attitudes towards the ecclesiastical reforms of the 1820s.

KEY WORDS: Franciscans nets, Bourbon Reforms, sermons, newspapers, revolution.

Recibido/Received 15-01-2008

Aceptado/Accepted 10-03-2008

La elección capitular franciscana de noviembre de 1806 permite a la facción peninsular prevalecer por sobre la criolla. Fray Ramón Álvarez, nacido en España, es elegido provincial con el apoyo de varios regulares, principalmente, con el de Fray Pantaleón García. García es criollo pero mantiene importantes contactos en el Viejo Mundo. Fray Pantaleón es uno de los regulares favoritos de la Corona en la región. Ha llegado a ser presidente de la Universidad de Córdoba y su prestigio se extiende desde los márgenes hasta el corazón mismo del imperio español. Los sermones de este franciscano rioplatense se publican en Madrid entre 1805 y 1810.

Fray Francisco de Paula Castañeda, nacido en Buenos Aires, forma también parte de la facción peninsular como García. A diferencia de éste, sin embargo, todavía no ocupa lugares prominentes en la orden a principios del siglo XIX.

La revolución del 25 de mayo de 1810 en Buenos Aires alcanza y transforma la vida de estos dos franciscanos. Aunque previamente miembros de la facción peninsular, tanto García como Castañeda se proclaman rápidamente por ella. Y se convierten en sus voceros. García será el encargado de dar el sermón del cuarto aniversario de la revolución en la iglesia Catedral de Córdoba; Castañeda lo será del quinto, en la de Buenos Aires.

La década de 1820 trae nuevos desafíos. García nunca perderá su rol de franciscano prominente y se mantendrá como guardián del convento de Córdoba durante la mayor parte del período. Castañeda no tendrá la misma suerte. A consecuencia de su febril actividad periodística en contra de la reforma religiosa porteña, Castañeda sufre constantes destierros que lo llevan desde Catamarca hasta Kaquel Huincul. Fray Francisco muere en 1832, Fray Pantaleón, un lustro antes.

En este trabajo, de carácter exploratorio, he procurado realizar un recorrido histórico de las primeras tres décadas del siglo XIX en el Río de la Plata a través de la vida de dos importantes franciscanos. Usando archivos eclesiásticos y civiles, sermones y diarios, intento identificar de qué manera, diferentes aconte- 
cimientos de largo alcance trasformaron las vidas de dos hispanoamericanos ${ }^{1}$. A partir de dos biografías pretendo brindar algunas sugerencias sobre el funcionamiento en el ámbito local de las políticas borbónicas, el impacto de la revolución dentro y fuera de los conventos, la transformación ideológica dentro de las Órdenes regulares y las intrincadas redes de relaciones sociales a ambos lados del Atlántico.

\section{DOS PERSONALIDADES DIFERENTES}

La Orden Franciscana o Seráfica fue fundada en el siglo XIII por San Francisco, con la obligación de no poseer cosa alguna, individual y colectivamente, sino vivir de limosna. Sus primeros representantes en América hacen su aparición hacia la primera mitad del siglo XVI junto a las expediciones de conquista. Algunos años después, la Orden ingresa en la región del Río de la Plata, para constituir la Custodia de San Jorge del Tucumán, súbdita de la provincia peruana de los Doce Apóstoles. Hacia fines de la época colonial, la Orden Seráfica cuenta, en la desde entonces llamada provincia de Nuestra Señora de la Asunción, perteneciente al virreinato del Río de la Plata, con 16 conventos, el Real Colegio y Universidad de Córdoba y también con varios pueblos de indios y capellanías, diseminados por todo el territorio ${ }^{2}$.

Pantaleón García nace en Buenos Aires en 1755 y se une a los franciscanos en la misma ciudad a los 18 años $^{3}$. Después de sus estudios para sacerdocio, continúa con su formación teológica, llegando a poseer el título de Lector y el cargo de Predicador. Pantaleón pronto destaca por sus capacidades oratorias e intelectuales. Aunque porteño, su carrera siempre se encuentra más cercana a Córdoba. En 1780, se doctora en lsu Universidad y en 1786 ejerce como Lector de Vísperas en la Universidad ${ }^{4}$.

\footnotetext{
${ }^{1}$ Aunque circunstancialmente se analiza en este trabajo el discurso de estos dos franciscanos, no es el objetivo del mismo profundizar en este tema, lo que corresponde a una segunda parte de este proyecto.

${ }^{2}$ Véase A. Millé, Crónica de la Orden Franciscana en la Conquista del Perú, Paraguay y el Tucumán y su convento del Antiguo Buenos Aires. 1212-1810, Buenos Aires, EMECE Editores, 1961.

${ }^{3}$ Salvo que se mencione lo contrario, los datos relacionados con el desempeño en la Orden franciscana de Pantaleón García y Francisco de Paula Castañeda han sido extrapolados de los siguientes documentos: Archivo Histórico de la Provincia de Buenos Aires (AHPBA). Archivo de la Real Audiencia. Reales Órdenes. Legajos 2.7.4,2.61; 2.7.4,2.62; 2.7.4,2.63; 2.7.4,2.67; 2.7.4,2.68; 2.7.4,2.73; $2.7 .4,2.75 ; 2.7 .4,2.76 ; 2.7 .4,2.77 ; 2.7 .4,2.78 ; 2.7 .4,2.79 ; 2.7 .4,2.83 ; 2.7 .4,2.85 ; 2.7 .4,2.86$ y $2.7 .4,2.87$.

${ }^{4}$ El título de Lector es otorgado por la Orden en mérito a los estudios efectuados por cada sacerdote. El religioso que luego de ser ordenado desea continuar con su formación, ingresa en alguno de los cuatro Estudios Generales que los franciscanos poseen en Córdoba (1), Paraguay (1) y Buenos Aires (2). Una vez concluidos sus siete años de estudio -tres de Filosofía y cuatro de Teología- el sacerdote egresa con el título de Lector, o profesor de Artes (Filosofía). Luego de enseñar tres años de Artes (Lógica, Física y Metafísica), un año de Cano y Cuatro de Teología (Prima o dogmática, Vísperas o moral,
} 
Su ascenso dentro de la jerarquía de la Orden es constante. Pantaleón desempeña las funciones de Examinador Provincial y Sinodal de la diócesis de Córdoba, entre otros cargos. En Córdoba, Pantaleón pronto ocupa numerosos puestos importantes de la facción peninsular y llega a ser Rector de la Universidad, cuando estaba todavía en manos de los franciscanos. A principios de siglo es elegido Ministro Provincial.

La carrera de Castañeda no es tan meteórica como la de García. Francisco de Paula nace en 1776 en Buenos Aires en el seno de una familia acomodada y donde la religión cumple un rol de importancia. Mientras que Francisco ingresa en la orden franciscana, su hermana lo hace en las Clarisas ${ }^{5}$. Francisco no se doctora a pesar de que sus padres le hubieran sustentado sus estudios en la prestigiosa universidad de Chuquisaca ${ }^{6}$. Castañeda se comporta rebeldemente bien temprano desafiando la estrategia familiar de sus padres.

Castañeda ingresa en el convento de la Recoleta de Buenos Aires donde «todo el año de noviciado me lo llevé durmiendo» y «era un escándalo para la comunidad el ver que todo lo erraba y que por causa mía en el coro... se trastornaba el orden». «La comunidad trató seriamente de declararme por inútil para la vida monástica». Castañeda, sin embargo, goza del favoritismo de Fray Cristóbal Gavica, Lector en Sagrada Teología y maestro de novicios en ese entonces quien «aseguraba que mi vocación era verdadera, y con mil razones persuadía esto mismo a los pares... para que no me negasen el voto» ${ }^{7}$. Como para Pantalón, el paso por Córdoba es también crucial para Cayetano. En 1798, Castañeda se ordena en esta ciudad pues en Buenos Aires no había obispo. En Córdoba le dan la cátedra de filosofía en la Universidad. Pantaleón y Cayetano establecen allí una relación que les proveerá de éxitos en el futuro.

Sagrada Escritura y Retórica), los Lectores adquieren el título de Jubilado. Al título de Jubilado se le anexa el número de veces que el sacerdote ha cumplido el ciclo. Es decir, «una vez jubilado», «dos veces jubilado», etc.

Otro título que goza de prestigio es el de Predicador General, grado por la Orden en mérito a la labor desarrollada por el religioso. El número de los mismos se mantiene uniforme, siendo de treinta y dos para la provincia. En cuanto a su distribución, observamos que siempre existe uno, por lo menos, por convento, salvo en la Universidad de Córdoba, hecho que se desprende de los objetivos académicos perseguidos por 6 misma. Todos los Predicadores Generales fueron por lo menos una vez Predicadores conventuales, cargo capitular asignado a un sacerdote por un período de cuatro años. No era un título, era un cargo. Se elegían dos por cada convento grande y uno por cada uno de los demás. Para mayor información véase a M. A. MEDINA, Los Dominicos en América Presencia y actuación de los dominicos en la América Colonial Española de los siglos XVI-XIX, Madrid, MAPFRE, 1992, pp. 56-57.

${ }^{5}$ N. AuzA, (ed.) Doña María Retazos. Francisco de Paula Castañeda, Buenos Aires, Taurus, 2001, p. 12.

${ }^{6}$ Ibidem, p. 14, Buenos Aires, 10 de octubre de 1822, 225.

7 Idem.

Hispania Sacra, LX

122, julio-diciembre 2008, 467-484, ISSN: 0018-215-X 


\section{LAS INVASIONES INGLESAS Y EL CAPÍTULO DE 1806}

La distinción entre criollos y Peninsulares ha sido por siglos una constante de la política colonial en América pero, en las últimas décadas de dominio español, la Corona procura ejercer un mayor control sobre cargos importantes como, por ejemplo, los de las Audiencias ${ }^{8}$. Esa preocupación se extiende al clero regular. A partir de la década de 1780 , la Corona solicita a los regulares listas periódicas de todos sus miembros, incluyendo nombres, cargos y orígenes, si eran Peninsulares o Americanos 9 .

Además, la Corona impone una rotación de cargos, obligando a las Órdenes a alternar sucesivamente entre un peninsular y un criollo para los más importantes. Este sistema, llamado alternativa, favorecería a priori a los peninsulares porque les asegura cada dos períodos alcanzar los cargos principales, aunque son minoría en todas las Órdenes ${ }^{10}$.

Probablemente a causa de esta presión monárquica, la existencia de facciones diferentes dentro de los conventos se torna pública en el Río de la Plata en 1806. En junio, las tropas inglesas invaden la región y toman Buenos Aires con casi ninguna resistencia inicial. Aunque los ingleses se rinden un mes y medio más tarde, durante el corto lapso de su gobierno, las Órdenes regulares de la ciudad les presentan expresamente una declaración escrita no sólo aceptando su autoridad sino también alabándolos, lo que es condenado por los habitantes de la ciudad. Las regulares están dispuestos -o deseosos- de continuar ejerciendo su oficio sin la presencia -o el control- de la corona española ${ }^{11}$. La única orden que no firma el documento es la betlehemita, la única también cuya mayoría de

\footnotetext{
8 Ver Mark Burkholder, «From Creole to Peninsular, the transformation of the Audiencia de Lima», en Hispanic American Review, 53.3 (1972).

${ }^{9}$ Esta listas corresponden a los documentos incluidos en la nota 3. Vale destacar qua en las listas, los religiosos nacidos en América figuran como indianos o como americanos, nunca como criollos. En este estudio se utilizan indistintamente las dos últimas denominaciones, ya que la palabra indiano modificó el significado qua tenía para la época.

${ }^{10}$ En las caso de los franciscanos, estas alternancias se dan cada cuatro años, que es cuando la Provincia realiza elecciones -denominadas Capítulos- para designar a los sacerdotes que ocuparán las diferentes funciones. El capítulo el punto más trascendental en la organización jerárquica de la orden. Están en juego, por un período de cuatro años, los destinos de todos los religiosos. Ver A. MiLlé. Para observar el funcionamiento general de la alternativa, ver Paul GANSTER, «Churchmen» en L. SCHELL Hoberman y S. Migden Socolow (ed.) Cities \& society in colonial Latin America, Albuquerque, University of New Mexico Press, 1986.

${ }^{11}$ A primera vista, la actitud del clero regular manifestaría cierto descontento para con la corona, lo cierto es que hacia esa época ya existía una experiencia probadamente feliz de convivencia entre clero católico y autoridades británicas. Desde 1763, los ingleses ocupaban el Canadá francés -en ese entonces Nueva Francia- permitiendo a los religiosos católicos el libre desempeño de su fe y de las tareas propias de su oficio.
} 
miembros es peninsular ${ }^{12}$. Vencidos los ingleses, sin embargo, la declaración de los regulares queda casi en el olvido.

En el caso de los franciscanos, noviembre de 1806 es el mes conflictivo. En el Capítulo de ese mes en Buenos Aires, que se celebra con retraso debido a la invasión, el peninsular Ramón Álvarez es elegido Ministro con el apoyo de Fray Pedro José Salivan, Provincial saliente, y de Fray Pantaleón García. Esta elección, no problemática cuando se hizo, será denunciada cuatro años más tarde por la facción criolla porque «el número de votantes fue aumentado para incluir los que García pensó eran sus partidarios» ${ }^{13}$.

Aunque existe una conexión lógica entre el lugar donde los frailes han nacido y la facción de la que toman parte, éste no es siempre el caso. La facción criolla está compuesta sólo por criollos pero la peninsular cuenta con miembros nacidos tanto en el Viejo como en el Nuevo Mundo. Ni López Carvallo, ni Sulivan ni García son Peninsulares. Su relación con la península, como la facción criolla denuncia a la Junta, son sus importantes conexiones en Madrid ${ }^{14}$.

\section{De CóRDOBA A MADRID}

Pantaleón García parece ser uno de los religiosos favoritos de la Corona. Además de haber sido rector de la Universidad de Córdoba, su prestigio recorre el Imperio español desde la periferia al centro. Seis volúmenes de sus sermones son publicados en Madrid en 180515. La historia de cómo esos volúmenes han llegado a la imprenta revela tanto las conexiones de García allende el Río de la Plata como las consolidadas redes sociales y de información que los franciscanos mantienen en el Imperio español.

A principios del siglo XIX, Fray Tadeo Ocampo, un franciscano misionero en el Colegio Apostólico de Moquegua, Perú. Ocampo, es un sólido referente no sólo en su comunidad sino en todo el Virreinato. Fray Tadeo, luego de obtener en España la categoría de Colegio de Propaganda Fide para el primer centro

\footnotetext{
12 Ver C. MAYo, Los Betlemitas en Buenos Aires: Convento, Economía y Sociedad, Sevilla, V Centenario del descubrimiento de América, 1991.

13 Ver C. BRUNo, v. VII, pp. 440-441.

${ }^{14}$ AHPBA. Real Audiencia, «Nómina de los Religiosos de la Provincia del Paraguay y tabla capitular de elecciones,»1806, 7.4.2.83. Parece ser que algo similar ocurría con los comerciantes de Buenos Aires hacia 1810. «...había una división entre los comerciantes privilegiados y los marginados... que era también, aunque no de forma absoluta, una división entre españoles y criollos». John LYNCH, «El reformismo borbónico e Hispanoamérica» en A. Guimera, (ed.) El Reformismo Borbónico, Madrid, Alianza, 1996, p. 47.

${ }^{15} \mathrm{P}$. GaRCía, Sermones panegíricos de varios misterios, festividades y santos, Madrid, Imprenta de Collado, 1805-1810. Esta colección contiene 80 sermones de días festivos y religiosos llevados a cabo principalmente en Córdoba.
}

Hispania Sacra, LX

122, julio-diciembre 2008, 467-484, ISSN: 0018-215-X 
de estudios de Moquegua, viaja a Roma a comienzos de 1796 para recibir, por disposición papal, el cuerpo de Santa Fortunata, cuyos restos yacían en la catacumba de Santa Ciriaca en Roma. A fines de ese año los restos de la Santa llegan a Moquegua ${ }^{16}$.

Desde entonces, Ocampo viaja con frecuencia a Europa vía Buenos Aires, ciudad donde ha profesado. En uno de esos viajes, se conecta con Pantaleón García y sus sermones. Rápidamente percibe el valor de éstos pues le «han estimulado a buscar el medio que se diesen a la prensa.» La publicación de los sermones no es algo de todos los días. Hasta en la propia España, se utilizan principalmente sermones traducidos del francés para las misas. La obra de García es «acaso en su genero la primera que ha salido de los claustros de Regulares de Indias $^{17}$.

En la presentación de la obra, Fray Tadeo describe el pacto entre las Órdenes regulares y la Corona española, pacto a partir del cual los franciscanos han llegado a América. En tanto las Órdenes regulares «acrecentaron el número de vasallos a los Monarcas de España, inspirándoles a un mismo tiempo con las ideas del cristianismo, las de sumisión y respeto del Soberano,» la Corona española «concedió a los regulares la facultad para erigir en aquella parte del globo casas y monasterios» ${ }^{18}$.

La publicación de los sermones de García, tiene como objetivo tanto profundizar el sentimiento religioso como consolidar la sumisión al soberano español ${ }^{19}$. Los sermones -que son impresos en 1805 y reimpresos en 1807 y 1810 circulan por el imperio y son utilizados por franciscanos de los dos continentes para inspirar sus propias prédicas ${ }^{20}$.

\footnotetext{
16 Santa Fortunata nació en Cesárea, Palestina, hija de una familia opulenta. Ella se convirtió al cristianismo en los primeros siglos después del nacimiento de esta fe. Según la leyenda un emperador pidió su mano, pero ella rehusó. Fue entonces perseguida y martirizada junto a sus hermanos. Fue puesta a disposición de los leones y los leones se arrodillaron ante ella. Fue sometida al fuego, pero las llamas no la tocaron. Fue condenada a morir por flechas, pero los arqueros fallaron el blanco. De alguna forma fue finalmente muerta y sus restos (incluyendo su cuerpo y una tela embebida en su sangre) llevados a Roma. «Retazos de la historia de Moquegua», Expreso de Lima, 14 de octubre de 2001.

${ }^{17}$ Fray Tadeo OCAMPO, «Presentación» en Sermones Panegíricos, pp. II-III.

18 Ibidem, p. VII.

${ }^{19}$ Los sermones de García confirman la alianza entre corona e iglesia remitiendo a la tradición pactista española. Para pactismo español en Hispanoamérica hacia principios del siglo XIX ver F. GUERRA, Modernidad e independencias: ensayos sobre las revoluciones hispánicas, Madrid, MAPFRE, 1992. Para Brading, sin embargo, el pacto ya estaba roto a fines del período colonial. D. BRADING, Una Iglesia asediada: el obispado de Michoacán, 1749-1810. México, Fondo de Cultura Económica, 1994.

${ }^{20} \mathrm{He}$ encontrado anotaciones como: «Del uso de fray Pascual de Rivero. Costo con sus seis compañeros: 179 reales» en algunos ejemplares que he estudiado. Entiendo que los sermones circulan en América y Europa aunque no puedo establecer estadísticamente la magnitud de su consumo.
} 
Además del discurso de García, llega a Madrid también el de otro franciscano americano, Fray Mariano de Velasco. En el último de los seis volúmenes de la obra se incluyen sermones de este franciscano paraguayo, tío del que sería dictador Gaspar de Francia, y que tendría un destacado aunque contradictorio desempeño después de 1810, al igual que García.

Otro que también tiene importante papel, ya desde antes de la Revolución, es Fray Pablo de Moya, visitador general y comisario general de todas las provincias y colegios de San Francisco en las Indias. A Moya «corresponde ser el mecenas de esta Obra» ${ }^{21}$. Fray Pablo es el enlace entre los religiosos americanos y Madrid y el principal actor de esta red tejida entre García, Ocampo, Velasco y él mismo. Después de 1810, como se verá más adelante, Fray Moya realizará esfuerzos denodados para continuar controlando las Órdenes desde Madrid.

Su prestigio en Madrid le permite manejar con ciertas maniobras espurias el Capítulo de 1806, elegir como provincial a su favorito Ramón Álvarez y asegurarse la presidencia del siguiente Capítulo a celebrar en 1810. No es Pantaleón quien queda más públicamente expuesto sino su aliado, Fray Pedro Josef Salivan. Este, que era el Provincial, antes del Capítulo traslada a algunos frailes opuestos a sus planes a destinos alejados del lugar de la votación. Fray Pedro Tadeo Bermúdez Quintana, de Buenos Aires, es derivado temporalmente a Montevideo y, en consecuencia, presenta una denuncia en contra de Salivan ante la Real Audiencia.

Quintana sostiene que a cambio de su traslado a Montevideo, otros varios frailes hacen el camino inverso a Buenos Aires a fin de votar a favor del candidato de Sulivan -Fray Álvarez. Denuncia además la existencia de asociaciones de frailes y menciona irregularidades en el Capítulo de 1774- irregularidades que Fray Pablo de Moya, quien ya era Comisario, decidió no investigar. Lo mismo hace el fiscal de la Audiencia. A pesar de generar un abultado legajo, acaba por desestimar la denuncia de Quintana ${ }^{22}$.

El funcionamiento de la red de 1 García y el juego de facciones dentro de las Órdenes permiten realizar tres inferencias. Primero, aún a fines del período colonial, las Órdenes regulares parecían seguir siendo cruciales para el plan de dominación español en América.

\footnotetext{
${ }^{21}$ Fray Tadeo OCAMPO, p. III. Durante el período colonial, cada Orden religiosa tenía un Comisario en España que ponía bajo su autoridad a los provinciales de esa Orden en América. La Asamblea del Año XIII, en el Río de la Plata, independizó a toda la Iglesia de ese territorio de cualquier autoridad eclesiástica situada fuera de sus límites. La Asamblea creó la Comisaría de Regulares que ponía bajo su autoridad a los provinciales de todas las Órdenes.
}

22 AHPBA. Archivo de la Real Audiencia. Legajo 7.5.38.

Hispania Sacra, LX

122, julio-diciembre 2008, 467-484, ISSN: 0018-215-X 
Segundo, el sistema de alternancia podía funcionar satisfactoriamente sin permitir alcanzar a los individuos nacidos en uno de los continentes los cargos principales durante varios períodos. Tercero, y derivado del anterior, las lealtades internas en los conventos franciscanos tenían más que ver con las redes sociales de los religiosos -que podían atravesar el Atlántico- que con sus orígenes. Todo esto estaría indicando que, en las Órdenes, el conflicto entre criollos y peninsulares no habría tenido la fuerza que se le ha adjudicado tradicionalmente en otros ámbitos, pues no era el origen de los religiosos lo que los enfrentaba sino la disponibilidad o no de redes de relaciones en la metrópoli. En este esquema, los criollos podían acomodarse a sus necesidades sin tener que enfrentarse a los peninsulares. Es más, el éxito de un criollo era mayor cuanto más se aliaba con estos.

\section{LA REVOLUCIÓN DE MAYO Y EL CAPÍTULO DE 1810}

El 25 de mayo de 1810, el mismo día que los criollos proclaman el nuevo gobierno en Buenos Aires, los franciscanos reúnen Capítulo en la ciudad para elegir sus autoridades para los próximos cuatro años. Este Capítulo es, en muchos sentidos, una reproducción religiosa de los acontecimientos políticos que ocurren fuera del convento.

Fray Francisco Javier López Carvallo es elegido Ministro Provincial. El Capítulo, como de costumbre, se divide entre una facción peninsular y una criolla. Carballo, nacido en América, forma parte de la facción de García, con redes en Madrid. Este último, presidente de Capítulo, aumenta «el número de parciales, introduciendo a voto a aquellos que creían sus parciales». Uno de ellos es Fray Francisco de Paula Castañeda ${ }^{23}$.

Francisco, que promedia su cuarta década de vida, comienza recién a destacarse como ya lo está haciendo hace años García. En el prólogo a los sermones en 1807, Ocampo destaca a García «por su exquisito y delicado gusto en la oratoria» $\mathrm{y}$ «por su profunda erudición teológica en la cátedra». Elogia incluso a los franciscanos de Buenos Aires «Barrientos, Basalos, Sulivanes, Monteros, Chambos, Villanuevas, Rodríguez» pero no llega a mencionar a Castañeda ${ }^{24}$. Cinco años después, sin embargo, Pantaleón García considera de fundamental importancia al voto de Castañeda para la votación.

Sin aceptar lo que el Capítulo decide, la facción criolla presenta una apelación a la Primera Junta, el nuevo gobierno que se ha constituido tras la Revolución. En noviembre, la Junta decide revocar toda medida tomada por el Capítu-

\footnotetext{
${ }^{23}$ El relato sobre el Capítulo de 1810 en C. BRUNO, v. VII, pp. 438-450.
}

${ }^{24}$ Fray Tadeo OCAMPO, pp. VII-VIII. 
lo presidido por García. Previsiblemente, un nuevo Capítulo llevado a cabo el 5 de febrero 1811 elige Ministro Provincial a Fray Cayetano José Rodríguez, un criollo sin conocidas conexiones en Madrid. Hay una nueva apelación, esta vez de la facción española. Mientras tanto, desde Cádiz, el Comisario Moya procura mantener a la Orden Franciscana bajo su control. Moya aprueba la elección de 1810 en febrero de 1811 y, nuevamente, en mayo del mismo año ${ }^{25}$.

La revolución y la independencia exacerban los conflictos internos de las Órdenes. Los desórdenes y la injerencia de las autoridades civiles en las Órdenes religiosas no son extraños pero la Revolución los trastoca ${ }^{26}$. A diferencia de lo que sucedía durante el período colonial, cuando los conventos se hacían eco de lo que sucedía extramuros, tan pronto se produce la Revolución, son los franciscanos los que apelan a las autoridades para resolver sus conflictos internos. Rotas las relaciones con Madrid y Roma después de la Revolución, algunos solicitan la intervención de la Junta, legitimando automáticamente la autoridad de Buenos Aires en asuntos religiosos. Involuntariamente, la orden franciscana es la primera institución en reconocerle a la Primera Junta el derecho de Patronato ${ }^{27}$.

La Revolución permite a los religiosos locales acceder a cargos de privilegio que les eran negados anteriormente por el sistema de alternativa o por su falta de conexiones con Madrid. Al mismo tiempo, ofrece una nueva fuente de disputas internas. Aunque los frailes pertenecen a una corporación, son también individuos con ansias de mejorar sus carreras profesionales, a veces a toda costa. La Revolución abre nuevas oportunidades dentro y fuera de los claustros. Esto es percibido rápidamente por los religiosos. Casimiro Ibarrola, por ejemplo, el que apela a la Junta en 1810, llegará a ser Comisario Provincial, el mismo cargo de mediador entre el Gobierno y las Órdenes que ocupaba Fray Moya. Pero con una sutil diferencia. En el nuevo contexto, Buenos Aires reemplazará a Madrid como centro de decisiones ${ }^{28}$. La nueva situación política canaliza las ambiciones personales.

25 Moya se mueve rápidamente apoyando la causa realista en todo el continente después de los acontecimientos que se van sucediendo en diferentes ciudades de Hispanoamérica a partir de 1810. en 1813, por ejemplo, envía una distinción por sus méritos a Fray Pedro José Hernández, monárquico, redactor de «Apología de la intolerancia religiosa» y miembro de la orden franciscana de Valencia, Venezuela. Ver «Apología de la intolerancia», http://club.telepolis.com/dioluis/

26 Ver J. PeIRE, El taller de los espejos: Iglesia e imaginario 1767-1815, Buenos Aires, Editorial Claridad, 2000, especialmente el capítulo 2.

${ }^{27}$ El Derecho de Patronato consiste en el conjunto de facultades especiales que los Papas concedieron a los reyes ibéricos a cambio de que estos apoyaran el establecimiento de la Iglesia Católica en América. Entre sus facultades se contaban la de proponer a la Corona los nombramientos de Virreyes, Capitanes Generales, Obispos, Oidores de Audiencia y en general todos los funcionarios administrativos del sistema colonial.

${ }^{28}$ Uno de los mayores conflictos de Fray Ibarrola como Comisario es con el Colegio de Propaganda Fide de San Carlos in 1814, cuyos miembros -también franciscano- eran mayoritariamente españoles. BRUNO, v. VIII, p. 54.

Hispania Sacra, LX

122, julio-diciembre 2008, 467-484, ISSN: 0018-215-X 
Los conventos no estaban aislados del resto de la sociedad colonial y, en consecuencia, eran atravesados por los mismos conflictos que sucedían extramuros. En ocasiones estos conflictos se plantaron más temprano en los conventos que en áreas teóricamente más conflictivas. Las disputas entre peninsulares y criollos en el ejército, por ejemplo, no explotaron hasta la Revolución de 1810 , un lustro más tarde que en las Órdenes ${ }^{29}$. La política penetró los conventos antes que las barracas.

\section{De Madrid a Buenos Aires}

A pesar de su participación en la facción peninsular durante el período tardo colonial, García continua siendo un referente de la orden en Córdoba después de la Revolución. Sus dotes de orador son conocidas y quizás por ello es elegido para predicar importantes sermones en fiestas públicas, como el aniversario de la Revolución en 1814 y la celebración del triunfo de Maipú en abril de 1818, ambos en la Catedral de Córdoba. En sus sermones patrióticos, García cita a Bacon, a Montesquieu y hasta la ruptura del contrato social, aunque sin mencionar a Rousseau, diciendo que el fundamento de la libertad: «es la obligación de cumplir el contrato social la liga las partes con el todo» ${ }^{30}$. Sin contrato, pues, no hay fidelidad.

Aunque puede utilizar un lenguaje ilustrado no son razones ilustradas las que fundamentan su apoyo a la Revolución sino otras más tradicionales. «Los Borbones que...concurriendo a las sacrílegas estipulaciones de Bayona, despreciaron el deber sagrado que contrajeron con los españoles de ambos mundos... se vieron por lo mismo incapaces de ocuparlo,» expresa en su sermón del 25 de mayo de $1814^{31}$. Y más adelante: «si Fernando nos abandonó... se rompió el contrato, se acabó el juramento» ${ }^{32}$. Sorprende, su descripción de los Borbones a quienes había elogiado en otros sermones durante el período colonial y de quienes habían sido sus aliados para mantener el control interno en la orden ${ }^{33}$. Gar-

\footnotetext{
${ }^{29}$ Ver Gabriel Di Meglio, «'Os habéis hecho temibles'. La milicia de la ciudad de Buenos Aires y la política entre invasiones inglesas y el fin del proceso revolucionario, 1806-1820» en Tiempos de América, 13 (2006), 151-166.

30 «Proclama sagrada dicha por su ilustre autor fray Pantaleón García, en la iglesia catedral de Córdoba, el 25 de mayo de 1814» en A. CARRANZA, (ed.,) El clero argentino de 1810 a 1830: oraciones patrióticas, Buenos Aires, Imprenta de M. A. Rosas, 1907, p. 101.

31 Ibidem, 96.

32 Ibidem, p. 101.

${ }^{33}$ Aunque la mayoría de los sermones son dedicados a evocar santos, en el sermón de la «Bula de la Santa Cruzada», García dedica amplias loas a Carlos IV. «Bula de la Santa Cruzada» en Sermones Panegíricos, Tomo VI.
} 
cía también apunta contra las Cortes, cuyas noticias de disolución el 10 de mayo de 1814 todavía no han llegado a Buenos Aires.

La Revolución, la guerra y la ruptura de relaciones con Madrid y con Roma producen, a su vez, una severa crisis de legitimidad y autoridad fuera y dentro de los conventos. Todo se congrega para complicar la situación de los franciscanos en la región. Entre ellos se suceden casos de embriaguez, desobediencia y hasta herejía. Pero Pantaleón siempre mantiene su posición y prestigio. García es encargado por el Obispo para investigar varias de estas cuestiones y se convierte en una suerte de agente inquisidor, luego de que esta es abolida por la Asamblea del año XIII ${ }^{34}$.

Casi al mismo tiempo, el franciscano paraguayo Fray Mariano Velasco, cuyos sermones habían circulado por el imperio español a fines del periodo colonial junto con los de Pantaleón, es también ahora un fervoroso revolucionario. Velasco es autor del panfleto «Proclama de un paraguayo a sus paisanos,» una arenga a los paraguayos en contra del Dictador Gaspar de Francia.

En la arenga, Velasco intenta convencer a sus compatriotas que no se separen de Buenos Aires. A cambio, Velasco, que reside en Buenos Aires, recibe la recomendación del Director Supremo Gervasio Posadas ante el Comisario General de Regulares, Casimiro Ibarrola, «por el interés que tiene en que sea atendido el mérito notable del referido Padre Velazco», Con tal apoyo, Velasco se convierte en Provincial de los franciscanos ${ }^{35}$.

Fray Francisco Castañeda no progresa demasiado en su carrera dentro de la orden. Hasta la Revolución de 1810, Francisco sólo ocupa cargos menores, quizás por su edad. Pero pronto sus sermones en Buenos Aires se vuelven famosos no sólo por su contenido sino más bien por su estilo y tono popular que le gana gran convocatoria.

Aunque formaba parte de la facción peninsular como García, sobre la base de ese prestigio, Castañeda es designado para pronunciar el sermón en Catedral de Buenos Aires el 25 de mayo de 1815. La causa revolucionaria convoca a sectores totalmente disímiles para difundirse. En su sermón, Castañeda elogia la Revolución porque ha cortado los lazos con una España en manos napoleónicas, pero hasta ahí llegan sus loas. «Ninguna cosa buena hemos hecho en seis años de revolución» ${ }^{36}$.

\footnotetext{
34 Ver Jorge Troisi Melean, «Los franciscanos de la Provincia de Asunción en la transición del periodo colonial al independiente (1780-1820), en V. AYrolo, (ed.) Estudios sobre clero iberoamericano, entre la independencia y el Estado-Nación, Salta, Universidad Nacional de Salta, 2006.

${ }^{35} \mathrm{El}$ documento está incluido en J. A. VÁzQUEZ, El doctor Francia, visto y oído por sus contemporáneos, Buenos Aires, EUDEBA, 1975, pp. 113-114.

36 «Sermón patriótico pronunciado en la Catedral de Buenos Aires el 25 de mayo de 1815 por Fray Francisco de Castañeda» en A. CARRANZA, p. 160.
}

Hispania Sacra, LX

122, julio-diciembre 2008, 467-484, ISSN: 0018-215-X 
En un estilo que asemeja a Joseph de Maistre, a quien seguramente ha leído $^{37}$, Castañeda adjudica la Revolución a la Providencia y no a los hombres: «y aún la del veinticinco de Mayo no es obra nuestra, sino de Dios» ${ }^{38}$. Castañeda puede ser popular pero no lo es con las autoridades. A diferencia de García, sus sermones son más punzantes y le crearán conflictos con las autoridades.

\section{Dos CAMINOS OPUESTOS}

En la década de 1820, varios gobiernos provinciales comienzan a repensar en la reorganización de las Órdenes religiosas. En sus comienzos, Bernardino Rivadavia, ministro del Gobernador de Buenos Aires, Martín Rodríguez, promulga una ley reformando las Órdenes religiosas, que coloca a los sacerdotes regulares bajo la protección del gobierno y bajo la jurisdicción eclesiástica ordinaria para asuntos espirituales. No reconoce la autoridad del ministro provincial. Establece una edad mínima de 25 para tomar los votos y fuerza a cada casa religiosa a no ser ocupada por más de 30 individuos $^{39}$.

En 1823, el gobierno de Cuyo, entonces perteneciente a la diócesis de Córdoba, publica una Reforma semejante a la instituida en la Provincia de Buenos Aires, limitando gravemente la autonomía del clero regular. Cuándo Fray Pantaleón García, entonces guardián del convento principal de Córdoba, afirma que, aunque carece de autoridad par aplicarla, concuerda con el espíritu de la reforma: «la reforma de los regulares... no es para destruir, sino para mejorar la vida monacal» ${ }^{40}$.

La ruptura de relaciones entre las Provincias Unidas y Roma y la actitud de los individuos de algunas Órdenes produjeron una severa crisis de autoridad en el alto clero y una sospecha sobre la legitimidad de la aplicación del derecho de Patronato. Este sentimiento es, en cierta manera, el que expresa García en su informe si bien acepta la necesidad de reforma, reflejando con ello también cierto acomodamiento de Pantaleón a los nuevos tiempos.

37 Joseph de Maistre (Saboya, 1774) es uno de los individuos más asociados a la reacción europea, De Maistre sostenía que la Revolución Francesa posteriores era la respuesta de Dios al atrevimiento del hombre de hacerse cargo de su futuro. Ver J. TROISI MELEAn, «Empezar la revolución: De Maistre y el estado de naturaleza en Rousseau». IV Congreso Nacional de Ciencia Política «Desempeño institucional y control democrático a fines de siglo», Buenos Aires, noviembre de 1999.

38 «Sermón patriótico pronunciado en la Catedral de Buenos Aires», A. CARranzA, p. 160.

${ }^{39}$ Ver R. DI STEFANO, El púlpito y la plaza. Clero, sociedad y política de la monarquía católica a la república rosista, Buenos Aires, Siglo XXI, 2004, pp. 193-248.

40 Archivo del Arzobispado de Córdoba (AAC), Legajo 3, «Expediente sobre la reforma de regulares en la provincia de Mendoza». 
Para entonces, los Guardianes de los conventos franciscanos se quejan con frecuencia de la desobediencia y la escasez de individuos en los conventos ${ }^{41}$. La situación no es nueva, pero adquiere un aspecto crítico en los 1820. El estado post-colonial considera a los sacerdotes franciscanos como agentes que pueden ser utilizados en su propia ventaja. Si en Buenos Aires, el Reformas rivadavianas procuran convertir la Iglesia en una rama del Estado ${ }^{42}$, en Córdoba, donde ninguna reforma fue aplicada, el gobierno no considera a los religiosos menos funcionales para controlar a la población. Varias disposiciones gubernamentales cordobesas de la década intiman a los superiores franciscanos a que envíen religiosos a las áreas rurales ${ }^{43}$. La estructura del Estado no estaba aún lo suficientemente desarrollada para reemplazar totalmente a los regulares por burócratas profesionales.

La Orden franciscana no es en 1820 la misma institución de antes. Para cumplir el requisito gubernamental, los Guardianes necesitan mandar a la zona rural los pocos individuos que ellos tenían en los conventos de la ciudad. Los superiores de Córdoba, donde Pantaleón García está pasando sus últimos días, escogen mantenerlos dentro de sus casas ${ }^{44}$. Hacia fin de la década, su contacto con las personas a quienes sirven, la meta principal de su existencia, es casi nulo.

Mientras García se va acomodando a los tiempos, Castañeda sigue una estrategia opuesta. Al mismo tiempo que el gobierno criollo empieza a demandar que los franciscanos se conviertan en agentes del Estado, varios periódicos, en su mayor parte publicados por Regulares, comienzan a luchar contra la reforma y la idea de la tolerancia religiosa que el gobierno de Buenos Aires promueve ${ }^{45}$. Fray Francisco Castañeda es, por lejos, el hombre más activo de este movimiento.

Castañeda publica hasta ocho periódicos al mismo tiempo en el Río de la Plata durante la década de 1820. El voto de pobreza les da pocas posibilidades

${ }^{41}$ AAC, Legajo 3, «Reclamo del Padre José Domínguez Ruiz», 1819; «Se niega permiso para franquear fuera de los conventos a los franciscanos», $1827 \mathrm{y}$ «El Cura de V. Del Rosario pide un coadjutor», 1827.

42 Ver M. E. BARRAL, De sotanas por la Pampa. Religión y sociedad en el Buenos Aires rural tardocolonial, Buenos Aires, Prometeo, 2006, pp. 29-48. Ya los Borbones habían comenzado a considerar la «utilidad» del clero para el ejercicio de su poder. Ver R. DI STEFANO, El púlpito y la plaza, p. 88.

${ }^{43}$ AAC, Legajo 3, «Franqueo del religioso Fray Gregorio Abrego», 1828. Paradójicamente esta era la actividad original de la orden, al menos, hasta fines del siglo XVI. Ver Francisco MORALES, «Mexican Society y the Franciscan Order in a Period of Transition, 1749-1859», en The Americas 54:3 (1998) 326.

${ }^{44}$ AAC, Legajo 3, «El Cura de V. Del Rosario pide un coadjutor», 1827.

${ }^{45}$ Diarios como El Cristiano Viejo, El Desengañador o el más sugerente El Intolerante -todos de Córdoba- incluyen a menudo en la década de 1820 editoriales contra la tolerancia religiosa, idea que El Argos y particularmente El Nacional de Buenos Aires promueven. Esta disputa constituye uno de los primeros debates nacionales en la prensa en Argentina. Biblioteca Dardo Rocha Universidad Nacional de La Plata, Colección Especial, «Periódicos 1820/1829».

Hispania Sacra, LX

122, julio-diciembre 2008, 467-484, ISSN: 0018-215-X 
institucionales de resistir las decisiones gubernamentales. El uso de la prensa es una forma creativa de hacerlo.

Paradójicamente, el espíritu díscolo y poco apegado a la disciplina conventual de Castañeda le permite escribir desde diferentes ciudades buscando imprentas que puedan publicar lo que propone. Su personalidad le provoca continuas sanciones del gobierno de Buenos Aires que lo destierra a Catamarca, Kaquel Huincul, Montevideo y Santa Fe ${ }^{46}$.

Adopta enfoques desafiantes y creativos. Los nuevos gobiernos se concentran en la esfera pública, un ambiente donde tradicionalmente participaban hombres. Sin embargo, Castañeda escribe especialmente diarios para mujeres, acentuando no sólo la virtud femenina sino también, y lo que es más importante, el papel de las mujeres en la religión y la identidad regional. La prensa es parte de la esfera pública pero con acceso a espacios aparentemente limitados a la esfera privada. Para llegar a ser un suscriptor de El Desengañador - uno de los diarios que escribe-, el lector necesita ser madre, o «matrona» ${ }^{47}$. Para Doña María Retazos -su periódico que adquirirá más fama- Castañeda utiliza un alias femenino, Doña María. Para fray Francisco, las mujeres son cruciales para mantener el sentimiento religioso vivo y son el objeto de los artículos de su prensa. Mientras las autoridades ilustradas de Buenos Aires las excluyen de la política, los religiosos más conservadores son los que le permiten tomar parte de lo público ${ }^{48}$. Paradójicamente, las ideas modernas promueven los papeles tradicionales del género femenino y la mayor parte de los religiosos más ortodoxos tratan de revolucionarlos. Las mujeres entran en la política esta década de 1820 anticipando lo que harían masivamente hacia principios del siglo siguiente ${ }^{49}$. El estudio de la relación entre mujeres, religión y prensa arroja nueva luz a importantes cuestiones comoquiénes eran realmente los guardianes de la religión católica.

Después de décadas de reacciones pasivas a cambios, durante la década de 1820 , Castañeda y otros religiosos toman la iniciativa para recuperar un lugar ocupado tradicionalmente e intentar revitalizar un catolicismo que parece congelado desde fines del periodo colonial.

\footnotetext{
46 N. AuZA, (ed.), pp. 9-39.

47 Toda la información sobre diarios en Biblioteca Dardo Rocha Universidad Nacional de La Plata, Colección Especial, «Periódicos 1820/1829.»

${ }^{48}$ Es interesante mencionar que en la Europa del siglo XVIII, las mujeres conformaban una gran parte del público lector aunque al mismo tiempo eran excluidas de la participación política. A largo plazo, empero, la entrada a la esfera pública literaria les dio los medios de desafiar los ideales prevalecientes de feminidad. Ver J. van Horn Melton, The Rise of the Public in Enlightenment Europe, Cambridge, Cambridge University Press, 2001, particularmente el capítulo 4.

49 Ver Sandra Mchee Deutsch, «Spreading Right-Wing Patriotism, Femininity, and Morality: Women in Argentina, Brazil, and Chile, 1900-1940», en V. GonZÁLEZ y K. KAMPWIRTH, (ed.) Radical Women in Latin America: Left and Right, University Park, Pennsylvania State University Press, 2001, pp. 223-48.
} 


\section{AlgunAS CONSIDERACIONES}

Los franciscanos del Río de la Plata sufren una transformación profunda en su relación con la sociedad y el Estado entre fines del periodo colonial y las primeras décadas de vida independiente. Si en el principio de este período parecían ser la rama principal de una de las instituciones coloniales más importantes, hacia la década de 1820, son sólo un grupo de personas que luchan por su supervivencia en un nuevo contexto.

Los acontecimientos externos como las invasiones inglesas o la Revolución exacerban los problemas que los franciscanos están experimentando al tiempo que crean nuevas oportunidades para algunos de sus miembros. La competencia interna para construir mejores carreras, generalmente un factor descuidado por los historiadores, parece haber sido tan perjudicial para la Orden como cualquiera de las medidas gubernamentales dirigidas contra ella ${ }^{50}$. La Revolución crea nuevas posibilidades, los regulares se reposicionan y los desplazados acuden a las nuevas autoridades. La crisis de la Orden franciscana en la región no sólo se produce por la aplicación de las Reales Cédulas de Madrid.

Frente a esa crisis, los miembros de las Órdenes parecen haber elegido entre dos caminos diferentes, dos estrategias opuestas dentro de la Iglesia que podrían rastrearse hasta hoy: una que se acomoda a las nuevas autoridades y otra que se rebela contra ellas.

Pantaleón García ha sido señalado tradicionalmente como ferviente patriota quizás por la inclusión de algunos de sus sermones patrióticos en el volumen editado por Adolfo Carranza. Cutolo, por ejemplo, describe a García como «un patriota devoto y un abogado de la independencia» y Fidel Iglesias, estudioso del clero rioplatense, lo señala como un ejemplo de las convicciones revolucionarias en algunos religiosos ${ }^{51}$.

Sorprende, sin embargo, que un religioso con un discurso tan favorable al Rey, como Pantaleón, pudiese crear otro posteriormente tan a favor de la Revolución. Esta situación podría explicarse por el juramento obligatorio de lealtad que los gobiernos revolucionarios hicieron firmar al clero. Podría entenderse,

${ }^{50}$ En este sentido, las Órdenes serían el campo -en el sentido dado por Pierre Bourdieu- donde los franciscanos -o agentes- competían para ser promovidos. En esta competencia, los franciscanos compartían un habitus común -las disposiciones internas del entorno donde socializaban- al que eventos externos, como la Revolución, rápidamente transformaron pero no eliminaron. Ver P. BOURDIEU, El sentido práctico, Madrid, Taurus, 1991.

${ }^{51}$ Ver A. CARRanza, ed., Fidel Iglesias, «The Platine Clergy, Independence, and the Rivadavian Reforms, 1806-27: Historical Overview and Select Bibliography», en Journal of Religious \& Theological Information, Vol 3(2) 2000, V. CuTOLo, Nuevo Diccionario biográfico argentino (1750-1930), Buenos Aires, 1971, III, p. 227 y M. M. EsANDI, 'García (Pantaleón)', DHGE 1180-1181.

Hispania Sacra, LX

122, julio-diciembre 2008, 467-484, ISSN: 0018-215-X 
como señala Jaime Peire, como consecuencia de la penetración del pensamiento ilustrado a las prácticas discursivas de los religiosos ${ }^{52}$.

El hecho de que los religiosos, que antes escribían sermones pro monárquicos se reinventen a sí mismos con sermones patrióticos se debe también a una cuestión práctica. Cuando todavía nadie posee en la región, los religiosos ya tienen una infraestructura de comunicación completamente desarrollada y efectiva a través de púlpitos y iglesias. Son, sobre todo, de los pocos intelectuales con capacidad de concebir un discurso coherente en la época. Las autoridades lo saben bien ${ }^{53}$. En este sentido, son intelectuales orgánicos al servicio de un grupo social en ascenso «que le dan homogeneidad y conciencia de su propia función, no sólo en el campo económico, sino también en el social y en el político» ${ }^{54}$.

Los religiosos con capacidades discursivas -los letrados coloniales- alcanzan luego de la Revolución, y llegado el momento modernizador, una suerte de disyuntiva entre continuar al amparo del poder estatal o derivar hacia la especialización profesional, que se comienza a ofrecer principalmente en la forma de periodismo ${ }^{55}$. En cierta manera, Pantaleón elige la primera opción y Francisco la segunda.

En cuanto al discurso en sí mismo, auque este no es el objetivo específico de este trabajo, es interesante evaluar cuán revolucionario era. Hemos visto sucintamente cómo el discurso de Pantaleón, mencionando autores ilustrado, contiene más bien una argumentación casi medieval para justificar la Revolución, algo, obviamente, mucho más claro en Castañeda ${ }^{56}$. Si la Revolución debe acudir a los religiosos para distribuir su mensaje, es necesario preguntarse cómo este mensaje es reinterpretado por el público.

En cuanto a la circulación del mensaje y de la información previa a la Revolución es necesario destacar su efectividad. Redes de información y de alianzas circulan a través del Atlántico desde y hacia Madrid conectando distantes puntos geográficos como Moquegua, Córdoba y Buenos Aires con la metrópoli. Posicionamientos profesionales y prestigio son bienes que circulan, se negocian y se intercambian por el control de los Capítulos desde la metrópoli. Las redes sociales atlánticas son tan poderosas que limitan el alcance de medidas guber-

52 Ver J. PeIRE, pp. 341-346.

${ }^{53}$ Ya desde fines del período colonial, se entendía, por ejemplo, que toda iniciativa de reforma debía contar con la colaboración del clero. Ver R. DI STEFANO, El púlpito y la plaza, p. 70.

${ }^{54} \mathrm{~A}$. GRAMSCI, «La formación de los intelectuales», en el libro Los intelectuales y la organización de la cultura, Ed. Nueva Visión, Buenos Aires, 1972.

55 El concepto de letrado en Á. Rama, La ciudad letrada, Montevideo, Comisión Uruguaya pro Fundación Internacional Ángel Rama, 1984.

${ }^{56} \mathrm{La}$ argumentación mediaval por la revolución es una continuación de la argumentación medival, o pactista, de fidelidad a la Corona.Ver nota 20. 
namentales que promueven las diferencias de status por el lugar de nacimiento. Un criollo astuto podía sobrellevar el accidente de su nacimiento y posicionarse en su profesión, si sabía con quien conectarse.

Concurrentemente, el control de Capítulos y sermones parece funcionar en forma efectiva. Sin embargo, en esa misma eficacia parece encontrar sus puntos débiles. Desplazados del sistema de redes principal, hay varios religiosos frustrados porque no se les permite progresar y hay también otros que han llegado a especializarse tanto en producir sermones que con mucha facilidad pueden transformar su contenido.

La Revolución crea nuevas reglas de juego a las que los religiosos se acomodan creativamente. Pantaleón elige integrarse; Francisco, resistir. Es un irreverente, como bien señala Rosalía Baltar ${ }^{57}$. Pero esa irreverencia la difunde convirtiéndose en un letrado moderno, un profesional de la escritura, que genera un discurso conservador de rechazo a lo moderno.

Castañeda es también un miembro del partido intransigente, como señala Roberto Di Stefano ${ }^{58}$. A esa intransigencia le agrega, sin embargo, un elemento adaptativo y sumamente original, la invitación a la mujer a ingresar en la esfera pública, idea rechazada por el discurso republicano. Castañeda entiende rápidamente que la condición sobre todo de madre, le permite a la mujer tomar acciones políticas extremas que no serían nunca toleradas a los hombres. Es una idea que sigue siendo poderosa aún en nuestros días.

${ }^{57}$ Rosalía BALTAR, «Francisco de Paula Castañeda o breve tratado sobre la irreverencia,» Espéculo, 34 (2006).

58 Ver R. DI STEFANO, pp. 205-214.

Hispania Sacra, LX

122, julio-diciembre 2008, 467-484, ISSN: 0018-215-X 